lumen. The peritoneum is thickened over the growth and an enlarged gland is adherent to the peritoneal surface which is much wrinkled and looks as if numerous adhesions had been torn through. Microscopically the central thickened part is invaded with columnar carcinoma down to the circular muscular layer. On each side the carcinomatous infiltration extends, gradually diminishing as it is traced up and down until the muscularis mucosæ becomes intact. The carcinomatous tissue occurs in large masses with an attempt at alveolar formation. The central part of the stricture has no epitbelium on the surface, which is formed of a band of fibrous tissue (with epithelial cells just below). The nuclei of the connective-tissue cells in this part are elongated, indicating long-standing disease. The epithelial cells are of a low cubical type and do not stain well. The vessels are not numerous and are fairly thick-walled, especially the inner coat. The most noticeable point in the section is the great development of connective tissue, causing the firmness of the stricture and probably indicating relative chronicity.'

Melbourne.

\section{ON THE QUESTION OF TRYPANOSOMA INFECTION IN MAN.'}

\section{By Professor F. MARCHAND, OF LEIPSIC;}

AND

J. C. G. LEDINGHAM, M.B., CH.B., B.Sc , M.A., of MARISGHal COLLEGE, ABERDEEN.

THE articles of Leishman, ${ }^{2}$ Donovan, ${ }^{3}$ and Ross ${ }^{4}$ prompt us to make the following communication. At a meeting of the Medical Society of Leipsic on Feb. 3rd, 1903, there were exhibited by one of us (Professor Marchand) microscopical preparations of the spleen, the liver, and the marrow from a peculiar case of splenomegaly accompanied by anæmia which was discussed in relation to the so.called Banti's disease. ${ }^{5}$ The case occurred in a man, aged 23 years, who had previously been quite strong and had taken part in the Chinese campaign. During the course of the war, however, and for eight months after its close he had enjoyed good health. About the end of January, 1902, he was taken ill in Leipsic, his complaint being loss of appetite and weakness. Towards the end of February attacks of headache and sweating began to intervene, occurring in a regular fashion every morning and afternoon. These symptoms were succeeded about the end of April by hoarseness and cough, for which he sought treatment in the clinic for diseases of the throat. Under suspicion of malaria the patient on June 7th was transferred to the Internal Medicine Clinic of Geheimrath. Professor Curschmann (St. Jacob's Hospital). Here the presence of an already extreme enlargement of the spleen was verified (its length being 235 centimetres). Repeated examinations of the blood with a view to the discovery of malarial parasites were always followed by a negative result. In the meantime the patient suffered continually from fever which was partly of a remittent and partly of an intermittent character but conformed to no regular type. Further, severe anæmia and diarrhoea set in. In the beginning of August tubercle bacilli were found in the sputum, a phthisical process in the left lung gradually developed, cystitis intervened and death followed on Dec. 12th.

At the post-mortem examination, which was performed in the Pathological Institute, there were revealed advanced disintegration of the left lung, dysenteric and tuberculous ulcers in the large intestine, cystitis, pyelonephritis, and an extreme enlargement of the spleen (length, 28 ctntimetres; breadth, 15 centimetres ; weight, 1750 grammes). The latter was somewhat soft and of a dark greyish-red colour, changing in parts to a lighter hue. The liver showed a reddish-brown colour and slight enlargement and the bone marrow was red. Film preparations from the spleen were unfortunately not made and the examination of the blood from the cadaver showed, apart from the anæmia, no important changes.

I Translation of an article appearing simultaneously in the Central blatt für Bakteriologie und Parasitenkunde. 2 Brit. Med. Jour., May 30th, 1903, p. 1253.

$$
\begin{aligned}
& 3 \text { Ihid., July } 11 \text { th, } 1903 \text {, p. } 79 . \\
& 4 \text { Ibid., Nov. 14th, 1903, p. } 1261 \text {. }
\end{aligned}
$$

5 Münchener medicinische Wochenschrift, No, xi., March 17th, 1903.
All the more surprising therefore was the result of the microscopical examination of sections of the spleen, the liver, and the marrow after fixation in Müller's fluid with 5 per cent. formol and hardening in alcohol. In the cells of the spleen pulp were found an extraordinary number of peculiar bodies of about $1 \mu$ to $1.5 \mu$ in diameter and which stained intensely with nuclear stains (hæma toxylin, carbol-fuchsin, \&c.) These bodies at first sight reminded one of micrococci but under the higher powers of the microscope presented themselves in the great majority of cases as distinctly ring-shaped. Some of the pulp cells showed rather advanced degeneration of their nuclei. The portal capillaries of the liver contained very numerous large cells of an amoeba type which in many cases completely blocked the lumen of the vessel. These large cells possessed in their interior besides their nucleus proper a very large number of the same small bodies above described which frequently lay in larger clumps in vacuoles of the cell protoplasm. Very often, too, besides the small bodies the protoplasm of these large cells included leucocytes, sometimes not a few. The marrow likewise contained in addition to the usual marrow cells large numbers of the same huge amoba-like phagocytes which inclosed in their interior extraordinarily numerous small bodies of the same nature, as well as red blood corpuscles. It is to be noted, however, that the bodies were never found in the interior of the red blood corpuscles and that pigment formation was never associated with them. Under high magnification the bodies exhibited surprisingly regular forms ; the majority were of a signet-ring shape with a clear centre; in a large number of them there lay beside this ring-shaped chromatin body a second and much more intensely stained (especially with carbol-fuchsin) dot of rounded or slightly elongated contour and which sat directly on the larger body or was separated therefrom by a small space. Generally this smaller body was situated with its long axis perpendicular to the surface of the larger or sometimes also tangential to it. Many of these bodies, and not only those lying in the cell vacuoles but also those which are to be found not infrequently jying free amongst the cells, were surrounded by a very fine faintly stained roundish or somewhat elongated halo of from $2 \mu$ to $3 \mu$ in diameter. (Vide diagram, copy of a drawing shown to the Leipsic Medical Society.)

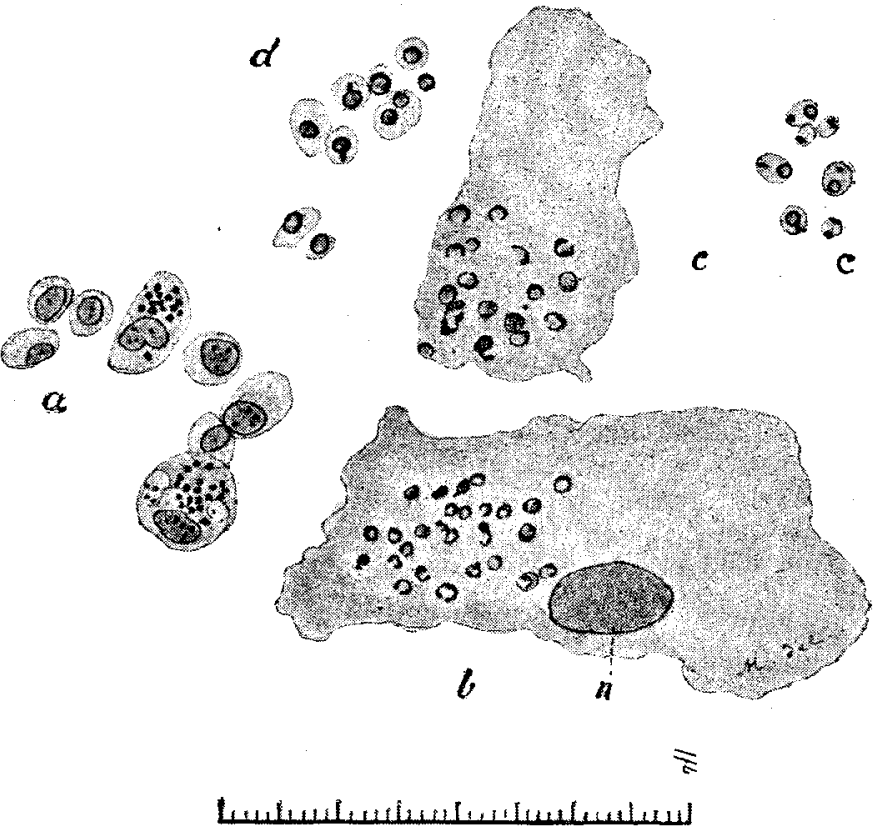

Explanation of diagram.-a, Several marrow cells (magnified 460 times). Some of the large cells contain the small ring-shaped bodies and one of them also contains vacuoles. $b$ and $c$, Two large phagocytes from the marrow containing numerous bodies which show in part signs of rather severe degeneration (only a portion of the same is shown in the diagram). $d$, Several isolated bodies from the marrow with their inclosing halos. $e$, Similar ones from the spleen (from $b$ to $e$ magnified 1250 times). These bodies gave us the impression of being something entirely unfamiliar to us ; we could not remember having seen anything like them before. The idea that they might have something to do with malarial plasmodia proved quite unentertainable, when in support of it one had to consider the history of the case as well as the course of the fever, although 
certain doubts still remained as to whtther some unknown form of malarial parasite, or, failing that, some quite strange protozoon, might possibly be present.

For lack of some fixed starting point Professor Marchand in the above-cited address on Banti's Disease believed it incumbent upon him to give it as his opinion that the bodies represented the product of degenerated cell nuclei. For this view the appearance of the cells of the spleen pulp seemed specially to speak as in certain situations their nuclei presented a disintegration to all possible forms of granules and shreds of chromatin substance which exhibited apparently all transition stages to the ring $s$ haped bodies lying amongst them. Still, the discovery was characterised by Professor Marchand as a yet unsolved riddle. The condition of the marrow and liver where no signs of nuclear degeneration were present served always to cast doubt upon the view that the bodies might represent nuclear products ; the oft-repeated and thorough examination of the bodies served to make their parasitic and protozoic nature still more certain. At the conference of the Deutscher Naturforscher und Aer'ze in Cassel Professor Marchand demonstrated the bodies to the German Pathological Society on Sept. 25th, 1903, but none of those present could decide as to the nature of the bodies. So also Professor Korschelt and Professor Brauer in Marburg and Professor Chun in Leipsic, who were good enough to make a personal examination of the preparations, were unable to give a decided opiricn. These gentlemen also had no doubt as to the parasitic nature of the bodies.

Unfortunately the cited communications in the British Medical Journal did not come to our knowledge till the end of November. The identity of the bodies found by Leishman in film preparations of the much enlarged spleen of a soldier who succumbed to a peculiar form of tropical fever in the cantonment of Dum. Dum near Calcutta, with those discovered by Donovan of Madras in April, 1903, in film preparations of the spleen (three times post mortem and once after splenic puncture during life, later repeated) can no longer permit of doubt after Leishman's exact description. Demonstration of the bodies in sections seems generally to have met with failure, while in our case their demonstration presented no difficulties. Leishman is of opinion that the bodies found by him in the spleen pulp are degeneration forms of that species of trypanosomata which were first discovered in man not long previously by Dutton ${ }^{6}$ in the case of a woman who had been infected in the Gambia region. He believes himself, therefore, forced to admit that trypanosoma disease occurs also in India, while this conclusion is still doubted by Donovan from the fact that no trypanosomata were found in the peripheral blood of the case examined by him during life. Leishman explains the appearance of the bodies in the following way. The trypanosomata lose their undulating membrane and the flagellum and only the shrunken macronucleus with the micronucleus remains behind. As a matter of fact, he was able to convince himself of the successive changes in this process after death in rats infected with Trypanosoma Brucei. Ross, as a result of his examination of Donovan's prepara. tions, finds certain difficulties in accepting Leishman's view because, according to him, in the case in which remains of trypanosomata were concerned, at least isolated flagella must still have been present. Leishman ${ }^{7}$ replies to Ross's objections on good grounds apparently. The reddish-stained rings round the chromatin body which were found in the preparations which Donovan made during life, and which gave support to the conclusion that these chromatin bodies were situated inside red blood corpuscles, might very well represent cysts or capsules. Still, up to the present Leishman considers it impossiole to decide whether the small bodies are new parasites or really altered trypanosomes. Laveran, ${ }^{8}$ who also had occasion to examine Donovan's preparations, believes that we have here to do with a new hæmatozoon which has no relation either to malaria or to trypanosoma and is to be referred to the genus piroplasma. He proposes the name piroplasma Donovani, but all the same gives the priority of the discovery to Leishman. (N.B - The bodies were first described by Professor Marchand. We do not, however, lay great stress on this fact as Leishman has the honour of having recognised their relation:hip to trypanosoma.) Laveran found the parasites lying partly free and partly. inclosed in red blood corpuscles. They

$$
6 \text { Brit. Mer. Jour., Sept. 20th, } 1902 .
$$

8 Bulletin de l'Académie de Médecine, No. 35, 1903, p. 238 were pear-shated or ovil, from " $.5 \mu$ to $3 \mu$ long and 1.5 $\mu$ broad, with a larger karyosome and a smaller acces. sory one which at times was joined on to the first by means of a short pedicle. The infected blood corpuscles, however, no longer stain like normal ones but are, as it were, washed out. These pale rings are surely identical with those above described in our case but which we could not recognise as being remains of red blood corpuscles but as constituent parts of the parasites themselves. Now, while we lay great value on the judgment of so great an authority on protozoa as Laveran we thould not like to omit to mention in this connexion that Laveran and Mesnil them. selves in their work on Trypanosoma Lewisi, ${ }^{\circ}$ Plate XI., Figs. 10 and 15, describe changes in these parasites as a result of phagocytic inclusion by leucocytes which at least are very like those described by us. The slight difference in size (in Fig 10) may well be due to an earlier stage in the change or to a difference in species. If then, as we consider probable, our case had also to do with a trypanosoma infection, we have certainly to admit that the infection took place during the patient's sojourn in China. On the strength of the correctness of the patient's history such a long latent period is certainly very extranrdinary. On the other hand, the possibility of a like infection also in our neighbourhood (Leipsic) wc uld not altogether be excluded, although in the present case which occurred in winter it would be more than improbable. The case will be described in greater detail later.

The following additional facts relating to this important cace have been ascertained quite recently by Professor Marchand. He says: "The stepfather of the deceased made in response to my inquiry the following important statements (which were in no way influenced by me) His son had been a soldier at Peking and had lain for a considerable period before the great walls. During the course of a long march be had received a fly bite on the foot, as a result of which his leg swelled enormously so that he could not draw on his brots and lay for about eight days in the lazaret. Of the further course of the illness nothing is known hy his parents. On his return to Germany the deceased made a short stay of about three months as night watchman in the barracks in the vicinity of Leipsic, and though bis disposition is said to bave shown a change to a peevish morose type he was not considered to be really ill.'

\section{A CASE OF LOBAR PNEUMONIA IN WHICH THE PHYSICAL SIGNS PERSISTED FOR EIGHT WEEKS ACCOMPANIED BY A VERY IRREGULAR TEMPERA- TURE.}

By J. M. BENNION, M.A., M.B., B.C. Cantab., M R C.S. Eng., L. R C P. LoND.,

rate house phystcian to the vetropoltTan hospital.

A woman, aged 32 years, was admitted into the Metropolitan Hospital on Juve 8tb, 1903. She was taken ill on June 3rd with a "shivering fit," severe headache, and pain in the right side On the 4th she was feverish and was suffering from sharp pain in the side and cough. From this date until admission the temperature was high, up to $104^{\circ} \mathrm{F}$. off and on. No phlegm was brought up. Her previous history was to the effect that she had ovariotomy performed 12 years previously and that she had suffered from pleurisy on the left side three months previously. Her parents were dead ; one sister suffered from phthisis.

On June 8th she complained of great pain in the right side. She looked ill but was not cyanosed. Her temperature was $1028^{\circ}$ and her pulse-rate was 120 . Her respirations were 60 per minute and rapid and shallow. She coughed a good deal but brought up no phlegm. Her chest was of a good shape, moving rapidly, but the expansion of the right side was deficient. Her heart was natural. Examination of the lungs yielded the foll. wing results. On the left side the note was good; the breath sounds were vesicular and

9 Annales de l'Institut Pasteur, 1901, vol. xv., p. 673. 